\title{
The Protective Role of Trauma Informed Attitudes on Perceived Stress Among Teachers and School Staff
}

\author{
Elizabeth P. Minne ${ }^{1} \cdot$ Gregory Gorelik $^{1}$ (1)
}

Accepted: 2 July 2021 / Published online: 24 July 2021

(C) The Author(s), under exclusive licence to Springer Nature Switzerland AG 2021

\begin{abstract}
Trauma-informed care (TIC), a system of behavioral treatment practices that focuses on understanding and responding to the effects of adverse experiences via empathic and non-punitive interactions, is a promising intervention for the treatment of academic and mental health problems among youth. However, the effect of TIC on caregivers themselves is uncertain. Even less is known about the relationship between TIC and the well-being of teachers and school staff. In the current study, we investigated the relationship between exposure to criminal victimization (a known predictor of stress), attitudes toward TIC, and perceived stress among a sample of public school teachers and staff members $(N=396)$. In line with our predictions, increased victimization was associated with increased perceived stress whereas TIC-favorable attitudes were associated with decreased perceived stress. In addition, older participants exhibited lower perceived stress than younger participants. We discuss the current study's limitations and the implications of the current findings for future research and mental health practice in schools.
\end{abstract}

Keywords Trauma-informed care $\cdot$ Perceived stress $\cdot$ Victimization $\cdot$ School mental health

\section{Overview of Trauma-Informed Care}

Trauma-informed care (TIC) is increasingly implemented in a variety of educational, medical, and mental health care settings. Baker et al. (2016) describe TIC as "service delivery that integrates an understanding of the pervasive biological, psychological, and social sequelae of ACEs [adverse childhood experiences] and trauma with the ultimate aim of ameliorating, rather than exacerbating, their effects" (p. 2). In the present paper, we refer to TIC as a system of behavioral treatment practices that focuses on understanding and responding to the effects of adverse experiences via empathic and non-punitive interactions between clients and service providers. In youth treatment settings, and particularly among youth experiencing complex trauma (multiple or chronic and prolonged developmentally adverse traumatic events), evidence indicates that TIC is effective in promoting school success, enhancing strengths, meeting psychological needs, and treating behavior problems and trauma-related

Elizabeth P. Minne

liz@vidaclinic.org

1 Vida Clinic PLLC, Austin, TX, US symptoms (Bartlett et al., 2018; Hamre \& Pianta, 2005). Services based in TIC principles have likewise shown effectiveness in improving functioning, behavioral and emotional regulation, and placement stability among youth in foster care (Murphy et al., 2017). Adult populations likewise exhibit positive outcomes after TIC-based interventions. In an examination of staff members at a not-for-profit psychotherapy and substance use treatment setting, Hales et al. (2017) observed marked improvements in staff members' perceptions of company processes, connectedness to-and being valued within - the company, work-role satisfaction, and satisfaction with management.

\section{TIC in Schools}

Although many children show remarkable resilience when faced with traumatic events, some children may show significant impairments, including social-emotional difficulties and significant barriers to learning (Burke et al., 2011; Copeland et al., 2007; McLaughlin et al., 2013). Summarizing the literature on trauma prevalence in the U.S., Saunders and Adams (2014) reported the following prevalence rates across nine categories of trauma among youth aged 0-17 years: sexual 
victimization: $13-17 \%$ of girls, $3-5 \%$ of boys; physical abuse and assault: 69-71\%; witnessed violence: $70 \%$; traumatic death of a loved one via criminal or vehicular homicide: $18 \%$; internet-assisted victimization: $9 \%$; teasing or emotional bullying: $29 \%$; disasters: $22 \%$; motor vehicle accidents: $10-21 \%$; and polyvictimization: $20-48 \%$. This research collectively indicates that approximately two out of three students in the US are likely to have experienced at least one traumatic event by age 17. Given that children experiencing trauma victimization and toxic stress ${ }^{1}$ spend much of their time in educational settings, schools have been considered the "entry point" for students to receive support around trauma-related issues that may affect their long-term development. As a result, there has been a national push to create more traumainformed systems of care in school settings.

To date, the bulk of research examining the effectiveness of trauma-informed initiatives in schools focuses on the degree to which external factors may impact educator ability to development of knowledge about TIC. Furthermore, building concrete knowledge is widely considered an important first step to becoming trauma informed (Ko et al., 2008; Substance Abuse and Mental Health Services Administration, 2014; Sundborg, 2019). In evaluating the Foundational Professional Development (FPD) training, a common method for introducing a new system-wide initiative in schools, McIntyre et al. (2019) found that mechanisms for increasing knowledge of TIC depended on systemic factors. Sundborg also found that Principal Support is important to consider when building educator commitment to TIC.

Some research highlights a connection between TIC and psychological variables in non-school provider settings, though less is known about such outcomes in school-based settings. Following a nine-month TIC training program, for example, Damian et al. (2017) reported improvements in climate safety, managerial support, and compassion satisfaction among participants working with traumatized youth. Contrary to what was predicted, however, after providing TIC treatment, staff experienced increased compassion fatigue - a measure that gauges staff burnout and secondary traumatic stress (i.e., stress carried over from individuals who experienced trauma directly). The researchers complemented these quantitative findings with qualitative responses that highlighted employees' heightened awareness of their own traumatic stress and need for self-care. Importantly, the researchers state that training in TIC "shifted participants' awareness of their emotional needs and stressors rather than increasing those stressors, which may be an important step for providers in moving toward better self-knowledge and self-care" (p. 755). On the other hand, it is possible that

\footnotetext{
1 Toxic stress is a state of prolonged physiological stress within a low social support context, often associated with adverse physical and mental health outcomes in childhood and beyond; Franke, 2014).
}

TIC training may have exacerbated providers' own stress or the stress stemming from exposure to traumatized individuals. In the current study, we offer some preliminary findings on the relationship between TIC knowledge and perceived stress and discuss the implications of TIC implementation on both shortand long-term well-being among educators and others who work with victimized youth.

\section{Victimization and Perceived Stress}

An abundance of research highlights the impact of victimization (criminal and otherwise) on an individual's psychological health and well-being. One of the psychological effects of victimization is perceived stress, which can further exacerbate the impact of victimization and cause chemical changes in the brain. Perceived stress is the extent to which people perceive that demands exceed ability to cope, thus undermining one's sense of power to be effective. Stoliker (2018), for example, found that the effects of different types of victimization (e.g., personal victimization, household/property victimization, cyberbullying, and physical/ sexual ex-partner abuse) on self-reported mental health and life satisfaction were either fully or partially mediated by perceived stress. That is, victimization-induced stress may be responsible for many of the psychological costs of victimization. At the physiological level, victimization-induced stress can be attributed to the hormone cortisol and changes in its regulatory processes. González-Cabrera et al. (2017), for instance, found that cyberbullying is associated with both increases in cortisol secretion and with self-reported anxiety and perceived stress, and that the relationship between cyberbullying and self-reported anxiety and perceived stress was partially explained by cortisol secretion. Östberg et al. (2018), however, found that even though being bullied predicts recurrent pain and perceived stress, it is associated with lower levels of cortisol. Whether victimization is associated with increases or decreases in cortisol, it seems clear that victimization changes the cortisol system's regulatory properties and that these changes are reflected in increased perceived stress. $^{2}$

\section{Relationship Between TIC and Perceived Stress Among Educators}

While literature on school mental health has addressed teacher stress, victimization, and TIC separately, there is less research on the connection between TIC attitudes and perceived stress

\footnotetext{
${ }^{2}$ Some research suggests that these changes are brought about by the effects of victimization on DNA regulatory mechanisms (e.g., Ouellet-Morin et al., 2013; but see Marzi et al., 2018, for contrary findings).
} 
among teachers and school staff. Experts acknowledge the importance of affect regulation in effective caregiving, including in teaching practices (Arvidson et al., 2011). Studies note that when students have a positive attachment with their educators, they have better mental health and social and academic outcomes (Venta, 2019), which is consistent with Bowlby's theory of attachment. On the other hand, teacher stress and burnout predict poorer teacher ratings of student behaviors, less intrinsic motivation for teaching, and negative expectations of students (Benita et al., 2018), all of which hinder the formation of positive student connections. Workrelated psychological distress is not only linked to problematic interactions with students, but it also may be associated with conflict in other life activities, such as problems with workfamily balance (Houlfort et al., 2018). However, studies suggest that educators' approach to helping others moderates their experience of burnout (Bamberger et al., 2017; Geller \& Bamberger, 2012), and educators' approach to selfcompassion is also an important determinant of workplace resilience (Patsiopoulos \& Buchanan, 2011).

Teachers working with students who have experienced traumatic victimization may be faced with unique challenges in the classroom, such as intense emotions, behavioral dysregulation, and a lack of trust for attachment figures that could exacerbate the stress that teachers may already experience (Buettner et al., 2016; Ferguson et al., 2012; O'Connor et al., 2012). Teacher internalization of trauma-informed beliefs could affect how well they are able to cope with the impact of working with complex youth who have experienced trauma. Shedding light on the relationship between educator stress and trauma-informed beliefs in high-trauma school communities may bring more importance to the role of teacher wellness in creating trauma informed school systems. Furthermore, a clearer understanding of such relationships can help in providing educators effective strategies for remaining resilient in demanding school environments.

In addition to the challenges that teachers face in managing stress (whether their students' or their own), there are second-order barriers that may prevent them from accessing the very resources needed to address their mental health needs. Lloyd (2018) discusses several barriers that teachers face in accessing support for students experiencing domestic violence at home, including lack of multiagency cooperation and market-driven fragmentation of school systems. Teachers may face similar barriers in accessing quality TIC training. On the promising side, the mechanisms that Lloyd suggests are useful in addressing institutional barriers to reporting and monitoring domestic violence among students (e.g., greater inter-agency cooperation, placement of a mental health professional within the school setting, the funding of extra-curricular clubs that incorporate mental health education, using a "whole child" approach that does not subordinate mental health needs to academic outcomes) might likewise be useful in educating teachers and school staff in TIC practices.

\section{The Current Study}

In the current study, we examine the relationship between the total number of victimizations public school teachers and staff members reported as having occurred in their school community, their attitudes toward TIC, and their level of perceived stress. Following from past research on the association between victimization and stress, we hypothesize that (1) a higher total number of reported victimizations will be associated with higher perceived stress among participants. Furthermore, if, as Damian et al. (2017) suggest, increase in traumatic stress following TIC training is due to an increase in internal focus, then the effects of TIC knowledge should lead to an eventual decrease in perceived stress to baseline levels or lower once the initial increase has subsided. We tracked participants' attitudes about TIC prior to the implementation of TIC training, so we predict that participants with favorable attitudes about TIC will have held such attitudes long enough for the attitudes to have reduced their perceived stress. Therefore, our second hypothesis is that (2) favorable attitudes about TIC will be associated with lower perceived stress among participants.

\section{Method}

\section{Population}

Three hundred ninety-six teachers and staff members (349 female, 46 male, 1 gender not reported) at 21 public schools in a large urban school district in Texas (20 elementary schools, 1 high school) completed a questionnaire at either a school mental health information session or via an Email link within a few days after the information session. Participants reported their age categorization in addition to other demographic information (see Table 1). Twenty participants reported their age as "18-24," 336 participants reported their age as "25-59," 23 participants reported their age as "60 and older," and 17 participants did not report their age (continuous age data were not available). All participants were treated ethically and in conformance with institutional review board guidelines (IntegReview IRB).

\section{Materials and Procedure}

Participants completed all measures electronically either on researcher-provided computer tablet devices or on their own digital devices. Participants provided victimization 
Table 1 Participant Demographics

\begin{tabular}{ll}
\hline Demographics Category & $n(\%)$ \\
\hline$N=396$ & \\
Age & \\
$18-24$ & $20(5.05)$ \\
$25-59$ & $336(84.85)$ \\
60 and Older & $23(5.81)$ \\
NA & $17(4.29)$ \\
Gender & \\
Female & $349(88.13)$ \\
Male & $46(11.61)$ \\
NA & $1(0.25)$ \\
Race & \\
American Indian/Alaskan Native & $1(0.25)$ \\
Asian & $6(1.52)$ \\
Hispanic or Latino & $165(41.67)$ \\
Multiple Races & $12(3.03)$ \\
White Non-Latino/Caucasian & $175(44.19)$ \\
NA & $20(5.05)$ \\
\hline
\end{tabular}

information in response to the question "Please indicate which of the following crimes have affected you or your school community. Leave blank if unknown." Participants then selected zero, one, or more victimizations from a list of 37 available victimization categories (e.g., "Child Physical Abuse or Neglect," "Stalking/Harassment," "Burglary," etc.-see Table 2). Participants then completed the 10-item short form of the Attitudes Related to Trauma-Informed Care (ARTIC) scale (higher scores indicate more favorable attitudes to TIC), a measure that gauges participants' attitudes to TIC-related constructs such as responding to students' problem behaviors and symptoms with flexibility and an emphasis on building healthy relationships vs. emphasizing rules and consequences (Baker et al., 2016). According to Baker et al., the10-item ARTIC short form captures the following five dimensions of TIC: caregiver belief that problem behavior is "external and malleable" rather than fixed and inherent; caregiver response to problem behavior with flexibility, safety, and relationship building over rules and consequences; empathy-focused versus control-focused caregiver attitude; caregiver sense of self-efficacy in being able to meet the demands of working with a traumatized population; and caregiver acceptance of support for the effects of vicarious trauma over ignoring vicarious trauma. ARTIC reliability in the current study $(\alpha=0.77)$ was lower than what was obtained by Baker et al. $(\alpha=0.82)$, though still in the acceptable range. Finally, participants completed the Perceived Stress Scale (PSS), a 10-item measure of participants' abilities to manage recently-occurring stressors (higher scores indicate more perceived stress; sample question: "In the last month, how often have you felt that you were unable to control the important things in your life?") (Cohen et al., 1983). Past studies indicate high PSS reliability ( $\alpha=0.84$ to 0.86 across three samples in Cohen et al.,'s original study; $\alpha=0.87$ in Barbosa-Leiker et al., 2013), which correspond to what was obtained in the current study $(\alpha=0.86)$. The presentation order of the measures was the same, but questions in the ARTIC and PSS scales were randomized across participants. All statistical analyses were perfomed using $\mathrm{R}$ (R Core Team, 2018).

\section{Results}

We generated a multiple linear regression with Victimization, ARTIC, and Age entered as predictor variables and PSS entered as the outcome variable. Visual inspection of the scatterplot of predicted versus residual values supported the linearity and homoscedasticity assumptions and visual inspection of the residuals histogram supported the normality of errors assumption. Predictor variables were not significantly correlated with one another, ruling out multicollinearity. The regression exhibited good model fit, $F(3,374)=26.66, p=0.000$, Adjusted $R^{2}=0.17$, where $\mathrm{PSS}=34.74+0.25$ (Victimization) -2.27 (ARTIC) -3.93 (Age) (See Table 3 for variable means and standard deviations). All three predictor variables independently predicted PSS score. There were no interactions. As hypothesized, higher Victimization values were associated with higher PSS scores, $\beta$ (Victimization $)=0.25,95 \%$ CI $[0.13,0.36]$, $p=0.000$, and higher ARTIC scores were associated with lower PSS scores, $\beta$ (ARTIC) $=-2.27,95 \%$ CI [-2.97, -1.57], $p=0.000$. In addition, older participants exhibited lower PSS scores than younger participants, $\beta($ Age $)=-3.93,95 \% \mathrm{CI}$ $[-5.64,-2.22], p=0.000$. In other words, with every additional victimization, perceived stress increased by 0.25 points, but decreased by 2.27 points with every one unit increase in favorable attitude toward TIC and decreased by 3.93 points as individuals transitioned from a younger age group to an older age group (see Fig. 1). There were no main effects or interactions between staff member gender or race with any variable of interest, except that White staff members reported a higher victimization frequency than Hispanic or Latino staff members, $F(5,369)=3.66, p=0.003$.

\section{Discussion}

Both hypotheses were supported: (1) a higher victimization count was associated with more perceived stress and (2) more favorable attitudes about TIC were associated with lower perceived stress. We also found that older age was associated with lower perceived stress. 
Table 2 Victimization Categories

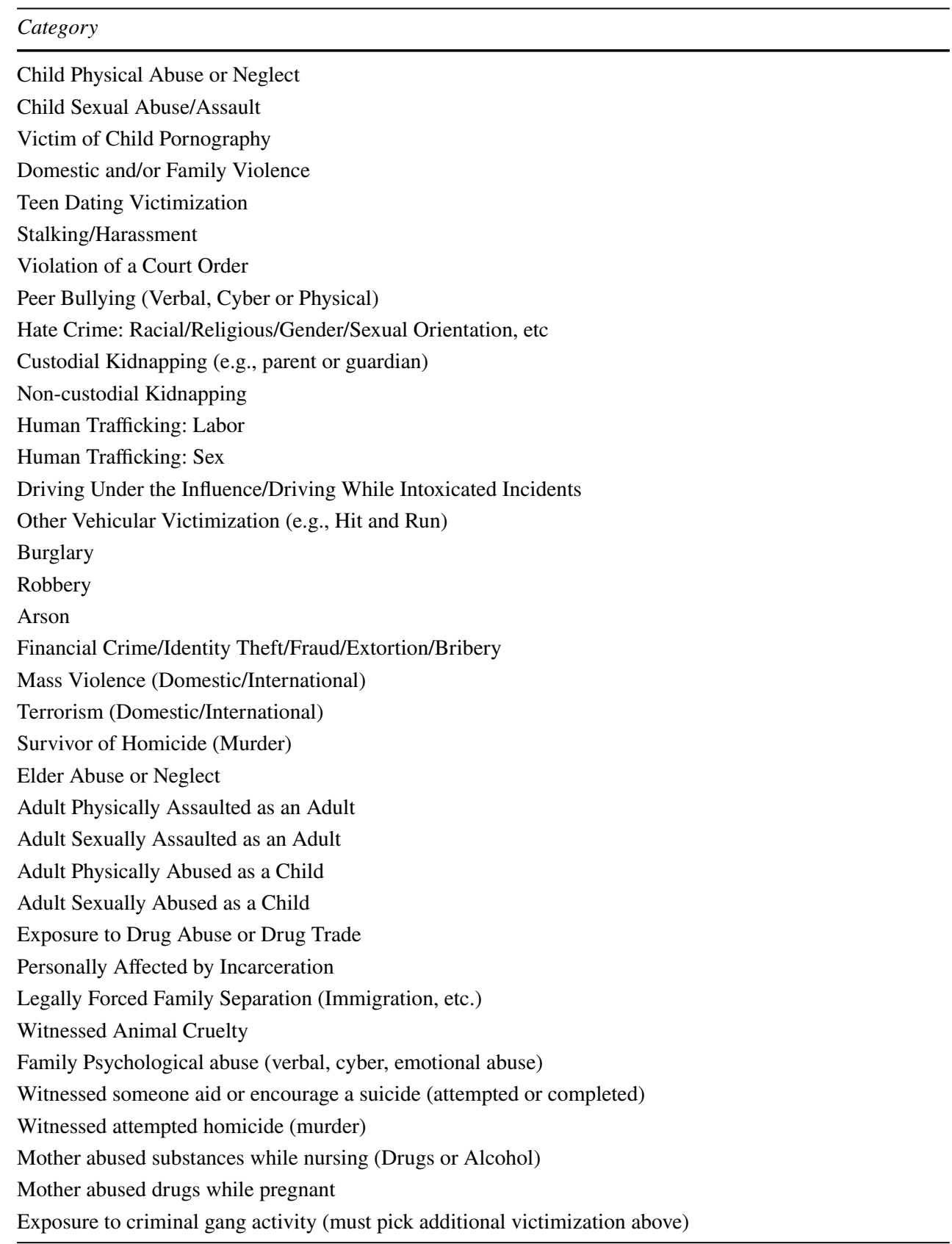

These findings lend additional support to the growing consensus that adverse experiences such as physical and psychological victimization are associated with increases in stress among individuals who experience them and among these individuals' caregivers (Baciu \& Vîrgă, 2018; Lee et al., 2018). Therefore, TIC may not just be effective at treating victims and others affected by trauma but may also have positive effects on the psychological health of their caregivers and service providers. Following Bamberger et al. (2017) and Geller and Bamberger (2012), a possible explanation is that caregivers with more favorable TIC attitudes may view
Trauma-Informed concepts as tools that are instrumental in empowering traumatized youth to develop long-term mastery, an approach that is found to be associated with positive caregiver well-being. Caregivers/educators with less favorable TIC attitudes, however, may use a helping approach that focuses more on expedience and short-term performance, an approach that is linked to quicker depletion of personal resources. Contrary to Damian et al. (2017) finding, we found evidence for a protective role of TIC-favorable attitudes on teachers' and staff members' perceived stress. In fact, our findings suggest that holding TIC-favorable attitudes has an even 
Fig. 1 Path diagram of unstandardized regression coefficients for the association between Victimization, ARTIC, Age, and PSS. $* * * p<.001$

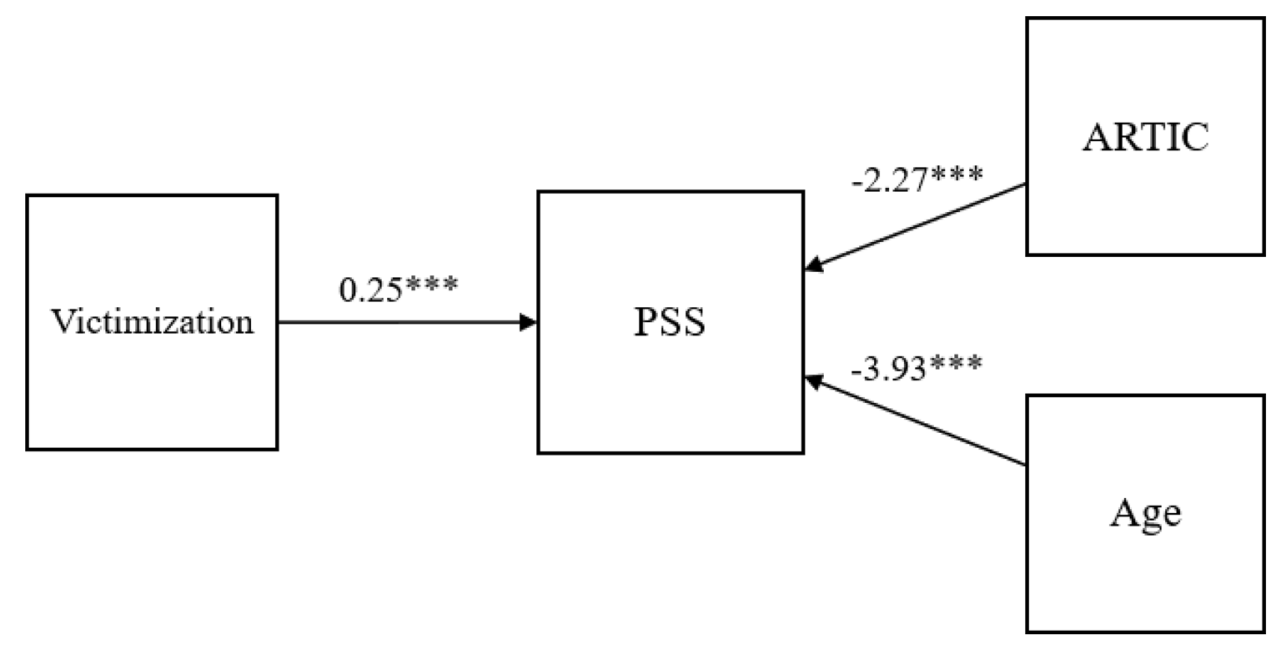

greater ameliorative effect on perceived stress than the exacerbating effect of victimization on perceived stress. This is not to discount Damian et al.'s finding of an increase in stress following TIC training. As Damian et al. suggest, TIC training may be associated with an increase in stress due to service providers' focus on their needs and stressors. Our findings suggest that this initial increase in perceived stress may open possibilities for subsequent reductions in stress as service providers apply TICinsights to their personal and professional lives. Finally, the importance of TIC for managing stress among young educators and school administrators is underscored by our finding that younger participants reported greater perceived stress than older participants, a finding that is in line with ongoing research on the attenuating effects of older age on perceived stress (Barbosa-Leiker et al., 2013; Heinze et al., 2017; Stone et al., 2017).

\section{Limitations}

Our findings, however, should be interpreted with some limitations taken into consideration. Although the current sample of staff members is demographically representative of the community at large, there may have been a self-selection bias on the part of staff members who chose to participate in a mental health information gathering event and to complete its associated survey.

Table 3 Variable Means and Standard Deviations

\begin{tabular}{lrl}
\hline Variable & \multicolumn{1}{c}{$M$} & \multicolumn{1}{c}{$S D$} \\
\hline Victimizations & 5.64 & 5.14 \\
ARTIC & 5.15 & 0.83 \\
PSS & 16.76 & 6.27 \\
\hline
\end{tabular}

Furthermore, as with all self-reports, and despite the high reliability and validity ratings of the ARTIC and PSS measures (Baker et al., 2016; Cohen et al., 1983), there is uncertainty as to whether the current findings reflect actual levels of participants' reported victimization, TIC-favorable attitudes, and perceived stress. Future research should aim at more objective measure of these constructs. Until then, the generalizability of the current findings is limited. A second limitation stems from the order of presentation of study materials. It is possible that, because the ARTIC was administered before the PSS, participants with higher ARTIC scores may have underreported their perceived stress whereas participants with lower ARTIC scores may have overreported their perceived stress. That is, TIC-attitudes may not have much influence on perceived stress in daily life but being prompted with TIC-related material leads individuals to misperceive their stress. A more counterbalanced design will help to address this issue moving forward. A third limitation stems from the fact that, because we do not have information about how long participants have held TIC-related attitudes and whether they had encountered TIC training in the past, our assumption that participants have held these attitudes for a prolonged time-period may be unwarranted. Finally, due to study limitations, participant age was collected as a categorical variable comprising three age groups, with the youngest and oldest groups comprising less than 30 participants each. Furthermore, the 25-59-year-old age group, which comprised most of the sample, includes too broad of an age range to assess age-related trends within the group (e.g., do TIC-attitudes and stress levels change as individuals transition to middle age?). Larger sample sizes comprising more diverse age groups and more continuous age measures should be implemented in the future. 


\section{Directions for Future Research}

It is possible that the strong association between TICattitudes and stress might reflect either a reverse causal relationship, whereby low stress influences individuals' willingness to endorse more supportive attitudes toward TIC, or that both stress and attitudes toward TIC are driven by a third, unidentified variable. It is also possible that perceived stress and TIC-related attitudes might be bi-directionally related. That is, increases in positive attitudes toward TIC might lead to decreases in perceived stress that, in turn, might lead to further increases in positive attitudes toward TIC. It would also be helpful to explore whether TIC attitudes are linked to different helping approaches among educators, which would further explain the relationship between trauma informed attitudes and perceived stress. All these possibilities warrant further investigation. With respect to future research on TIC and its implementation, because the ARTIC measures participants' default TIC-related attitudes, it is difficult to know how the construct measured by the ARTIC might be related to that of TIC programs in general. Although there is increasing theoretical agreement on foundational TIC concepts (see Baker et al., 2016), there is still a lack of standardization of TIC implementation in practice. The attachment-centered ARC framework, for example, shows promise in addressing caregiver stress throughout TIC treatment implementation (Hodgdon et al., 2016), whereas other TIC programs may not. The extent to which some forms of treatment are more capable of managing caregiver stress and, more generally, whether some degree of caregiver stress may be unavoidable-or even necessary-throughout the course of TIC training or treatment implementation are topics that require further investigation. In addition, a more thorough understanding of the relationship between age and wellbeing-related constructs (including, but not limited to, stress) can go a long way toward an understanding of the lifespan-related challenges and opportunities for workers in educational as well as physical and mental health settings. Finally, TIC interventions may not benefit everyone equally. Individual and demographic differences in physiological and psychological response to stress, differences that are associated with both adaptive and maladaptive effects across the lifespan (see McEwen, 2017), may likewise cause individuals to respond differently to TIC interventions. Further investigation of these differences is necessary if we are to avoid a one-size-fits-all approach to remedying stress and improving mental health among teachers.

\section{Conclusion: Toward a Trauma-Informed Educational Setting}

The outcomes reported in the current study underscore the importance of trauma-informed interventions for addressing victimization-induced stress and well-being among teachers and school staff. We believe that the benefits of such an approach will not only be experienced by teachers and school staff members but also by the students under their care. Previous studies highlight the toll of educator-level stress on students' own physiological stress response (Oberle \& Schonert-Reichl, 2016) and the direct and indirect effects of teacher stress and burnout (i.e., emotional exhaustion, depersonalization, reduced personal accomplishment) on children's academic outcomes (Wong et al., 2017). The protective influence of positive teacher-student relationships and, in particular, trauma-informed interventions (especially when implemented system-wide and encompassing both primary and secondary caregivers) show promise in addressing the psychosocial harms of student-level peer victimization and in improving children's psychobehavioral health (Murphy et al., 2017; Sulkowski \& Simmons, 2018). The authors of the current manuscript are currently administering a multi-systemic, school-based behavioral health program that uses trauma-informed approaches to address the psychological needs of child victims of crime. The program employs an ecological model that incorporates a child's family members, school staff, and the wider school community in the child's treatment. Our goal is to measure the effects of TIC training intervention on student, family, and school staff well-being over time. We likewise encourage researchers, educators, and caregivers to incorporate trauma-informed approaches in their research and practice and to creatively implement such approaches to foster well-being in school communities and beyond.

Acknowledgements The authors would also like to thank the therapists and staff at Vida Clinic PLLC for providing school outreach and for their efforts in administering survey material.

Authors Contribution The authors are grateful to the two anonymous reviewers who provided invaluable feedback on an earlier draft of the current manuscript.

\section{Declarations}

Informed Consent All participants were treated in accordance with IRB-approved ethical principles and signed a digital informed consent. (IntegReview IRB \#: 2019VidaClinic01).

Research Involving Human and Animal Participants This research included human participants only.

Conflict of Interest The authors have no conflicts of interest to disclose. 


\section{References}

Arvidson, J., Kinniburgh, K., Howard, K., Spinazzola, J., Strothers, H., Evans, M., \& Blaustein, M. (2011). Treatment of complex trauma in young children: Developmental and cultural considerations in application of the ARC intervention model. Journal Child Adol Trauma, 4(1), 34-51. https://doi.org/10.1080/19361521.2011. 545046

Baciu, L., \& Vîrgă, D. (2018). The prevalence of secondary traumatic stress among Romanian social workers: A replication study. Social Work Review/Revista de Asistenta Sociala, 17(3). Retrieved from http://eds.a. ebscohost.com.ezproxy.fau.edu/eds/pdfviewer/pdfviewer?vid=2\&sid= 278a1385-f425-4780-8a99-d9b136b81383\%40sdc-v-sessmgr06

Baker, C. N., Brown, S. M., Wilcox, P. D., Overstreet, S., \& Arora, P. (2016). Development and psychometric evaluation of the Attitudes Related to Trauma-Informed Care (ARTIC) scale. School Mental Health, 8(1), 61-76. https://doi.org/10.1007/s12310-015-9161-0

Bamberger, P. A., Geller, D., \& Doveh, E. (2017). Assisting upon entry: Helping type and approach as moderators of how role conflict affects newcomer resource drain. Journal of Applied Psychology, 102(12), 1719-1732. https://doi.org/10.1037/apl0000243

Barbosa-Leiker, C., Kostick, M., Lei, M., McPherson, S., Roper, V., Hoekstra, T., \& Wright, B. (2013). Measurement invariance of the perceived stress scale and latent mean differences across gender and time. Stress and Health, 29(3), 253-260. https://doi.org/10.1002/smi.2463

Bartlett, J. D., Griffin, J. L., Spinazzola, J., Fraser, J. G., Noroña, C. R., Bodian, R., \& Barto, B. (2018). The impact of a statewide traumainformed care initiative in child welfare on the well-being of children and youth with complex trauma. Children and Youth Services Review, 84, 110-117. https://doi.org/10.1016/j.childyouth.2017. 11.015

Benita, M., Butler, R., \& Shibaz, L. (2018). Outcomes and antecedents of teacher depersonalization: The role of intrinsic orientation for teaching. Journal of Educational Psychology, Advance Online Publication. https://doi.org/10.1037/edu0000328

Buettner, C. K., Jeon, L., Hur, E., \& Garcia, R. E. (2016). Teachers' social-emotional capacity: Factors associated with teachers' responsiveness and professional commitment. Early Education and Development, 27(7), 1018-1039. https://doi.org/10.1080/ 10409289.2016.1168227

Burke, N. J., Hellman, J. L., Scott, B. G., Weems, C. F., \& Carrion, V. G. (2011). The impact of adverse childhood experiences on an urban pediatric population. Child abuse \& neglect, 35(6), 408413. https://doi.org/10.1016/j.chiabu.2011.02.006

Cohen, S., Kamarck, T., \& Mermelstein, R. (1983). A global measure of perceived stress. Journal of Health and Social Behavior, 24, 385-396. https://doi.org/10.2307/2136404

Copeland, W. E., Keeler, G., Angold, A., \& Costello, E. J. (2007). Traumatic events andposttraumatic stress in childhood. Archives of General Psychiatry, 64(5), 577-584. https://doi.org/10.1001/ archpsyc.64.5.577

Damian, A. J., Gallo, J., Leaf, P., \& Mendelson, T. (2017). Organizational and provider level factors in implementation of traumainformed care after a city-wide training: An explanatory mixed methods assessment. BMC Health Services Research, 17(1), 750-759. https://doi.org/10.1186/s12913-017-2695-0

Ferguson, K., Frost, L., \& Hall, D. (2012). Predicting teacher anxiety, depression, and job satisfaction. Journal of Teaching and Learning, 81(1), 27-42. https://doi.org/10.22329/JTL.V8I1. 2896

Franke, H. A. (2014). Toxic stress: Effects, prevention and treatment. Children, 1(3), 390-402. https://doi.org/10.3390/children1030390

Geller, D., \& Bamberger, P. A. (2012). The impact of help seeking on individual task performance: The moderating effect of help seekers' logics of action. Journal of Applied Psychology, 97(2), 487-497. https://doi.org/10.1037/a0026014

González-Cabrera, J., Calvete, E., León-Mejía, A., Pérez-Sancho, C., \& Peinado, J. M. (2017). Relationship between cyberbullying roles, cortisol secretion and psychological stress. Computers in Human Behavior, 70, 153-160. https://doi.org/10.1016/j.chb.2016.12.054

Hales, T. W., Nochajski, T. H., Green, S. A., Hitzel, H. K., \& WoikeGanga, E. (2017). An association between implementing traumainformed care and staff satisfaction. Advances in Social Work, 18(1), 300-312. https://doi.org/10.18060/21299

Hamre, B. K., Pianta, R. C. (2005). Can instructional and emotional support in the first-grade classroom make a difference for children at risk of school failure? Child Development, 949-967. https://doi. org/10.1111/j.1467-8624.2005.00889.x

Heinze, J. E., Stoddard, S. A., Aiyer, S. M., Eisman, A. B., \& Zimmerman, M. A. (2017). Exposure to violence during adolescence as a predictor of perceived stress trajectories in emerging adulthood. Journal of Applied Developmental Psychology, 49, 31-38. https:// doi.org/10.1016/j.appdev.2017.01.005

Hodgdon, H. B., Blaustein, M., Kinniburgh, K., Peterson, M. L., \& Spinazzola, J. (2016). Application of the ARC model with adopted children: Supporting resiliency and family well being. Journal of Child \& Adolescent Trauma, 9(1), 43-53. https://doi.org/10.1007/ s40653-015-0050-3

Houlfort, N., Philippe, F. L., Bourdeau, S., \& Leduc, C. (2018). A comprehensive understanding of the relationships between passion for work and work-family conflict and the consequences for psychological distress. International Journal of Stress Management, 25(4), 313-329. https://doi.org/10.1037/str0000068

Ko, S. J., Ford, J. D., Kassam-Adams, N., Berkowitz, S. J., Wilson, C., Wong, M., \& Layne, C. M. (2008). Creating trauma-informed systems: Child welfare, education, first responders, health care, juvenile justice. Professional Psychology: Research and Practice, 39(4), 396-404. https://doi.org/10.1037/0735-7028.39.4.396

Lee, J. J., Gottfried, R., \& Bride, B. E. (2018). Exposure to client trauma, secondary traumatic stress, and the health of clinical social workers: A mediation analysis. Clinical Social Work Journal, 46(3), 228-235. https://doi.org/10.1007/s10615-017-0638-1

Lloyd, M. (2018). Domestic violence and education: Examining the impact of domestic violence on young children, children, and young people and the potential role of schools. Frontiers in Psychology, 9, 2094. https://doi.org/10.3389/fpsyg.2018.02094

Marzi, S. J., Sugden, K., Arseneault, L., Belsky, D. W., Burrage, J., Corcoran, D. L., \& Odgers, C. L. (2018). Analysis of DNA methylation in young people: Limited evidence for an association between victimization stress and epigenetic variation in blood. American Journal of Psychiatry, 175(6), 517-529. https://doi.org/ 10.1176/appi.ajp.2017.17060693

McEwen, B. S. (2017). Neurobiological and systemic effects of chronic stress. Chronic Stress, 1, 2470547017692328. https://doi.org/10. $1177 / 2470547017692328$

McIntyre, E. M., Baker, C. N., \& Overstreet, S. (2019). Evaluating foundational professional development training for traumainformed approaches in schools. Psychological Services, 16(1), 95-102. https://doi.org/10.1037/ser0000312

McLaughlin, K. A., Koenen, K. C., Hill, E. D., Petukhova, M., Sampson, N. A., Zaslavsky, A. M., \& Kessler, R. C. (2013). Trauma exposure and posttraumatic stress disorder in a national sample of adolescents. Journal of the American Academy of Child \& Adolescent Psychiatry, 52(8), 815-830. 10.1016/j.jaac.2013.05.011

Murphy, K., Moore, K. A., Redd, Z., \& Malm, K. (2017). Traumainformed child welfare systems and children's well-being: A longitudinal evaluation of KVC's bridging the way home initiative. Children and Youth Services Review, 75, 23-34. https://doi.org/ 10.1016/j.childyouth.2017.02.008 
Oberle, E., \& Schonert-Reichl, K. A. (2016). Stress contagion in the classroom? The link between classroom teacher burnout and morning cortisol in elementary school students. Social Science \& Medicine, 159, 30-37. https://doi.org/10.1016/j.socscimed. 2016.04.031

O'Connor, E. E., Collins, B. A., \& Supplee, L. (2012). Behavior problems in late childhood: The roles of early maternal attachment and teacher-child relationship trajectories. Attachment \& Human Development, 14(3), 265-288. https://doi.org/10.1080/14616734. 2012.672280

Östberg, V., Låftman, S. B., Modin, B., \& Lindfors, P. (2018). Bullying as a stressor in mid-adolescent girls and boys-associations with perceived stress, recurrent pain, and salivary cortisol. International Journal of Environmental Research and Public Health, 15(2), 364. https://doi.org/10.3390/ijerph15020364

Ouellet-Morin, I., Wong, C. C., Danese, A., Pariante, C. M., Papadopoulos, A. S., Mill, J., \& Arseneault, L. (2013). Increased serotonin transporter gene (SERT) DNA methylation is associated with bullying victimization and blunted cortisol response to stress in childhood: A longitudinal study of discordant monozygotic twins. Psychological Medicine, 43(9), 1813-1823. https://doi.org/10. 1017/S0033291712002784

Patsiopoulos, A. T., \& Buchanan, M. J. (2011). The practice of selfcompassion in counseling: A narrative inquiry. Professional Psychology: Research and Practice, 42(4), 301-307. https://doi.org/ 10.1037/a0024482

R Core Team. (2018). R: A language and environment for statistical computing. R Foundation for Statistical Computing. Vianna, Austria. Retrieved from https://www.R-project.org/

Saunders, B. E., \& Adams, Z. W. (2014). Epidemiology of traumatic experiences in childhood.Child and Adolescent Psychiatric Clinics, 23(2), 167-184. 10.1016/j.chc.2013.12.003
Stoliker, B. E. (2018). An examination of the effects of different victimization types on psychological and behavioral health outcomes and the mediating role of stress. Victims \& Offenders, 13(6), 834858. https://doi.org/10.1080/15564886.2018.1491436

Stone, A. A., Schneider, S., \& Broderick, J. E. (2017). Psychological stress declines rapidly from age 50 in the United States: Yet another well-being paradox. Journal of Psychosomatic Research, 103, 22-28. https://doi.org/10.1016/j.jpsychores.2017.09.016

Substance Abuse and Mental Health Services Administration S. (2014). SAMHSA's concept of trauma and guidance for a traumaInformed approach. HHS Publication.

Sulkowski, M. L., \& Simmons, J. (2018). The protective role of teacher-student relationships against peer victimization and psychosocial distress. Psychology in the Schools, 55(2), 137-150. https://doi.org/10.1002/pits.22086

Sundborg, S. A. (2019). Knowledge, principal support, self-efficacy, and beliefs predict commitment to trauma-informed care. Psychological Trauma: Theory, Research, Practice, and Policy, 11(2), 224-231. https://doi.org/10.1037/tra0000411

Venta, A. C. (2019). Contribution of schools to mental health and resilience in recently immigrated youth. School Psychology, 34(2), 138-147. https://doi.org/10.1037/spq0000271

Wong, V. W., Ruble, L. A., Yu, Y., \& McGrew, J. H. (2017). Too stressed to teach? Teaching quality, student engagement, and IEP outcomes. Exceptional Children, 83(4), 412-427. https://doi.org/ $10.1177 / 0014402917690729$

Publisher's Note Springer Nature remains neutral with regard to jurisdictional claims in published maps and institutional affiliations. 